\title{
Proximal femoral nail antirotation II in fixation of intertrochanteric fractures: retrospective and prospective observational study
}

\author{
Arvind Kumar S. M., Arun Kumar B.*
}

Department of Orthopaedics, PSG IMS and R, Coimbatore-4, Tamil Nadu, India

Received: 24 February 2020

Revised: 18 April 2020

Accepted: 20 April 2020

*Correspondence:

Dr. Arun Kumar B.,

E-mail: arunbala2007@gmail.com

Copyright: (C) the author(s), publisher and licensee Medip Academy. This is an open-access article distributed under the terms of the Creative Commons Attribution Non-Commercial License, which permits unrestricted non-commercial use, distribution, and reproduction in any medium, provided the original work is properly cited.

\begin{abstract}
Background: Intertrochanteric fractures occur mostly in elderly patients, and the outcome may be extremely poor if there is prolonged bed-rest. The best treatment for trochanteric fracture remains controversial. Proximal femoral nail antirotation (PFNA) II has excellent fit as the design is adapted to the anatomical situation of small statured patients also. It has a medial lateral angle of 5 degrees. It has several distal locking options viz static/dynamic. Objective of this study was to observe the operating time, blood loss and fracture union in intertrochanteric fractures treated with PFNA II from the data collected from patient's case sheets and post-operative X-rays.

Methods: 25 patients who were operated with PFNA II for unstable intertrochanteric fracture were selected using random selection and following parameters were noted from the records.

Results: The mean age of the participants is $70.72 \pm 8.55$ years with range from 52 years to 89 years. The mean duration was 1.98 hours \pm 0.66 . The median duration was 2 with interquartile range from 1.5 to 2.5 hours. Mean blood loss was estimated to be $390 \mathrm{ml} \pm 62.78$. The median blood loss was $370 \mathrm{ml}$ with interquartile range from 360 to $420 \mathrm{ml}$.

Conclusions: The PFNA II is an ideal implant for unstable intertrochanteric fracture since stable intramedullary fixation can be achieved with almost $100 \%$ union in the studied population.
\end{abstract}

Keywords: Intertrochanteric fractures, PFNA2, Proximal femoral nailing

\section{INTRODUCTION}

Intertrochanteric fractures occur mostly in elderly patients, and the outcome may be extremely poor if there is prolonged bed-rest. The best treatment for trochanteric fracture remains controversial. ${ }^{1-3}$ Many methods have been recommended. ${ }^{4-6}$ Stable fixation that allows early mobilization is the treatment of choice. Cephalomedullary devices are favored as the treatment for unstable A2 and A3 fractures, especially in the absence of medial buttressing. ${ }^{2,3,6,7}$ While there are numerous operative devices for treatment of trochanteric fractures, none of them are totally free of complications. There is no advantage to an intramedullary nail versus a sliding compression hip screw for low-energy pertrochanteric fractures classified by arbeitsgemeinschaftfür osteosynthesefragen/orthopaedic Trauma Association (AO/OTA) 31-A1 and A2, specifically given its increased cost and the lack of evidence to show decreased complications or improved patient outcome. ${ }^{4}$

Proximal femoral nail antirotation (PFNA II) has excellent fit as the design is adapted to the anatomical situation of small statured patients also. It has a medial lateral angle of 5 degrees. It has several distal locking options viz static/dynamic.

Insertion of the blade compacts the cancellous bone. The inserted PFNA blade achieves an excellent fit through 
bone compaction and requires less bone removal compared to a screw. ${ }^{6,7}$

Boyd and Griffin (1949) classified fractures in the trochanteric area of femur into 4 types. Their classification is useful in planning treatment and estimating prognosis. ${ }^{8,13}$

Type 1 fractures that extend along the intertrochanteric line from the greater to the lesser trochanter. Reduction usually is simple and is maintained with little difficulty. Results generally are satisfactory.

Type 2 comminuted fractures, the main fracture being along the line, but with multiple fractures in the cortex. Reduction of these fractures is more difficult because the comminution can vary from slight to extreme.

Type 3 fractures that are basically subtrochanteric with at least one fracture passing across the proximal end of the shaft just distal to or at the lesser trochanter.

Type 4 fractures of the trochanteric region and the proximal shaft, with fracture in at least two planes, one of which usually is the sagittal plane and may be difficult to see on routine anteroposterior radiographs. If open reduction and internal fixation are used, two plane fixations are required because of the spiral, oblique, or butterfly fracture of the shaft.

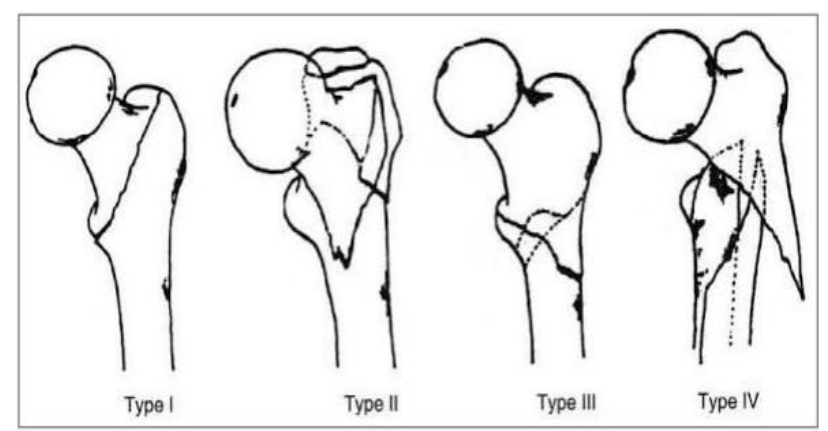

Figure 1: Boyd and Griffin classification of intertrochanteric fracture. ${ }^{13}$

\section{Aim}

The aim of the study is to observe the operating time, blood loss and fracture union in intertrochanteric fractures treated with PFNA II. Observe the operating time, blood loss and fracture union in intertrochanteric fractures treated with PFNA II from the data collected from patient's case sheets and post-operative X-rays.

\section{METHODS}

It is a retrospective observational study which included 25 Patients diagnosed to have intertrochanteric fractures and treated with PFNA II at our hospital (PSG) during June 2017 to July 2018 were selected for this study.

\section{Inclusion criteria}

Inclusion criteria were all Intertrochanteric fractures treated with PFNA II. Patients willing for treatment and given written informed consent.

\section{Exclusion criteria}

Exclusion criteria were pathological fractures, infection, treated after 3 weeks of trauma, patients medically unfit for surgery, compound fractures associated with vascular injuries, ipsilateral femoral shaft fractures and pelvic fractures, patients not willing for treatment, and open reduction done.

25 patients who were operated with PFNA II for unstable intertrochanteric fracture were selected using random selection and following parameters were noted from the records. The criteria taken into consideration were duration of surgery, intra operative blood loss, postoperative X-ray for assessment of union after 6 weeks and the data was statistically analysed.

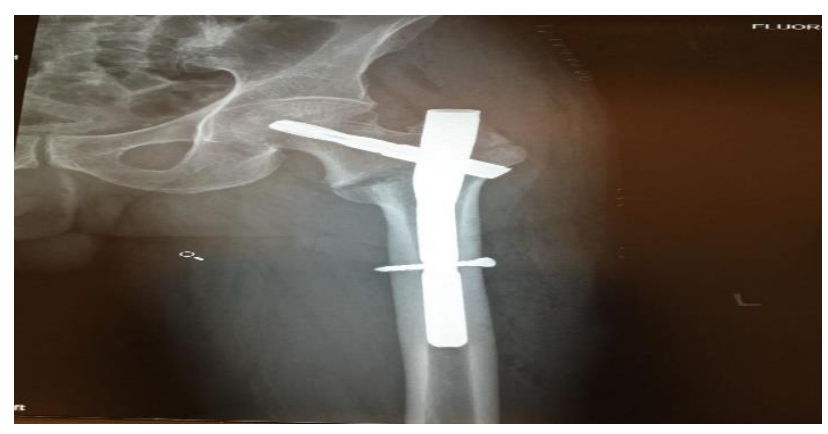

Figure 2: Immediate post-operative $\mathrm{X}$-ray of patient 10.

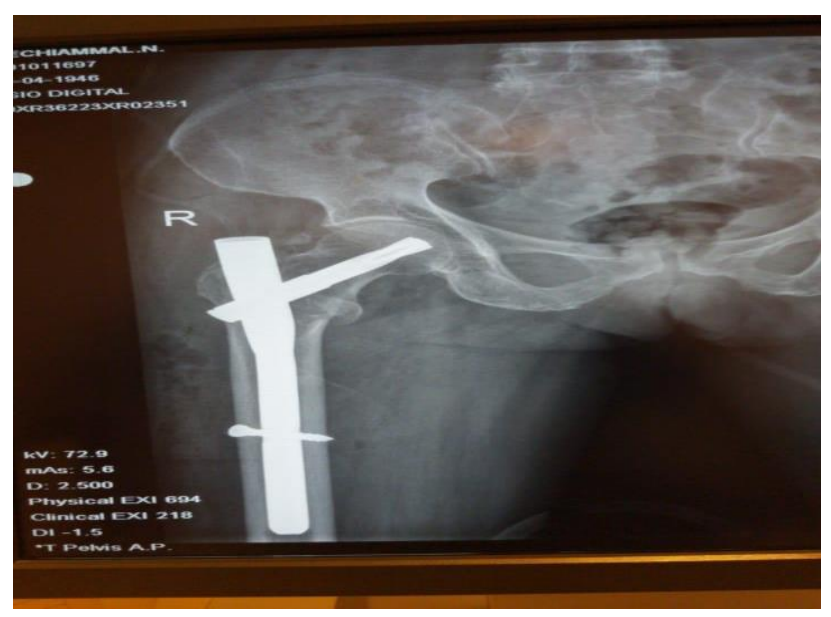

Figure 3: 6 Weeks follow up X-ray of patient 5.

\section{RESULTS}

The mean age of the participants is $70.72(\mathrm{SD} \pm 8.55)$ years with range from 52 years to 89 years. 
Table 1: Duration of Surgery.

\begin{tabular}{|ll|}
\hline S. no & Duration (hours) \\
\hline $\mathbf{1}$ & 2.5 \\
\hline $\mathbf{2}$ & 2 \\
\hline $\mathbf{3}$ & 1.5 \\
\hline $\mathbf{4}$ & 1.5 \\
\hline $\mathbf{5}$ & 3 \\
\hline $\mathbf{6}$ & 1.5 \\
\hline $\mathbf{7}$ & 3 \\
\hline $\mathbf{8}$ & 2 \\
\hline $\mathbf{9}$ & 1.5 \\
\hline $\mathbf{1 0}$ & 1.5 \\
\hline $\mathbf{1 1}$ & 3 \\
\hline $\mathbf{1 2}$ & 2 \\
\hline $\mathbf{1 3}$ & 2 \\
\hline $\mathbf{1 4}$ & 1 \\
\hline $\mathbf{1 5}$ & 1.5 \\
\hline $\mathbf{1 6}$ & 1 \\
\hline $\mathbf{1 7}$ & 2 \\
\hline $\mathbf{1 8}$ & 2.5 \\
\hline $\mathbf{1 9}$ & 1.5 \\
\hline $\mathbf{2 0}$ & 3 \\
\hline $\mathbf{2 1}$ & 2.5 \\
\hline $\mathbf{2 2}$ & 1.5 \\
\hline $\mathbf{2 3}$ & 2.5 \\
\hline $\mathbf{2 4}$ & 2 \\
\hline $\mathbf{2 5}$ & 1.5 \\
\hline & \\
\hline
\end{tabular}

Table 2: Blood loss.

\begin{tabular}{|ll|}
\hline S. no & Blood loss $(\mathbf{m l})$ \\
\hline $\mathbf{1}$ & 480 \\
\hline $\mathbf{3}$ & 370 \\
\hline $\mathbf{4}$ & 400 \\
\hline $\mathbf{5}$ & 360 \\
\hline $\mathbf{6}$ & 520 \\
\hline $\mathbf{7}$ & 320 \\
\hline $\mathbf{8}$ & 550 \\
\hline $\mathbf{9}$ & 360 \\
\hline $\mathbf{1 0}$ & 450 \\
\hline $\mathbf{1 1}$ & 310 \\
\hline $\mathbf{1 2}$ & 360 \\
\hline $\mathbf{1 3}$ & 370 \\
\hline $\mathbf{1 4}$ & 390 \\
\hline $\mathbf{1 5}$ & 420 \\
\hline $\mathbf{1 6}$ & 400 \\
\hline $\mathbf{1 7}$ & 380 \\
\hline $\mathbf{1 8}$ & 360 \\
\hline $\mathbf{1 9}$ & 310 \\
\hline $\mathbf{2 0}$ & 360 \\
\hline $\mathbf{2 1}$ & 450 \\
\hline $\mathbf{2 2}$ & 330 \\
\hline $\mathbf{2 3}$ & 390 \\
\hline $\mathbf{2 4}$ & 440 \\
\hline $\mathbf{2 5}$ & 320 \\
\hline & 350 \\
\hline
\end{tabular}

The mean duration was 1.98 hours $(\mathrm{SD} \pm 0.66)$. The median duration was 2 with interquartile range from 1.5 to 2.5 hours. Mean blood loss was estimated to be $390 \mathrm{ml}$ (SD \pm 62.78$)$. The median blood loss was $370 \mathrm{ml}$ with interquartile range from 360 to $420 \mathrm{ml}$.

\section{DISCUSSION}

PFNA II is a newer device used in fixation of intertrochanteric fracture. Previously, most surgeons used the dynamic hip screw as the choice of implant for intertrochanteric fracture. In this study the advantages of the device have been studied by means of operating time, blood loss and fracture union. Among the cases studied the mean blood loss was found to be very low when compared with that of dynamic hip screw (DHS) as quoted in the few studies. The operating time has been found to be reduced (statistically significant $\mathrm{p}<0.001$ ) when this is compared with that of DHS. ${ }^{10-14}$

The blood loss in our study was lesser in this study when compared to most other studies that used DHS. ${ }^{12-16}$ The difference in blood loss was statistically significant $(p<0.001)$ with $95 \%$ C.I. Since this method of nail insertion uses small incisions and less soft tissue dissection, the mean blood loss is very less.

The simple operating steps reduces the duration of the surgery when compared to that of the DHS. The mean duration of surgery was less than 2 hours. This difference is statistically significant $(\mathrm{p}<0.001) .{ }^{18-24}$ There was almost $100 \%$ union noted in this study than the previous studies, hence there is no worry for the operating surgeon about the fracture union. ${ }^{13,27-31}$

\section{CONCLUSION}

The PFNA II is an ideal implant for unstable intertrochanteric fracture since stable intramedullary fixation can be achieved with almost $100 \%$ union in the studied population. The PFNA II was easy and quicker procedure with minimally invasive technique and minimal blood loss when compared with previous studies that used the dynamic hip screws.

\section{Limitations}

Small sample size and short duration of follow up.

Funding: No funding sources

Conflict of interest: None declared

Ethical approval: The study was approved by the institutional ethics committee

\section{REFERENCES}

1. Babhulkar S. Management of trochanteric fractures. Indian J Orthopaedics. 2006;40(4):210.

2. Rockwood C, Green D, Bucholz R. Rockwood and Green' fractures in adults, Philadelphia: Lippincott Williams and Wilkins; 2006. 
3. Singh A, Thong G, Laloo N, Singh A, Singh S. Management of trochanteric fractures. Indian $\mathbf{J}$ Orthopaedics. 2006;40(2):100.

4. Cooper A. Fractures and Dislocations of Joints.10th ed. London: 1839.

5. Bick E. Source Book of Orthopaedics. New York: Hafner; 1968.

6. Moore H. Treatment of intertrochanteric fractures of femur. JBJS. 1983;65:262-7.

7. Schumpelick W, Jantzen OM. A new principle in orthopaedic treatment of trochanteric fractures of femur. J Bone Joint Surg Am. 1955;37(4):693-8.

8. Whitmann R. A new method of treatment for fractures of the neck of the femur, together with remarks on coxavara. Ann Surg. 1902;36:746.

9. Massie WK. Extracapsular fractures of the hip treated by impaction using a sliding nail - plate fixation. Clin Orthop. 1962;22:180-202.

10. Jewet. One-piece angle nail for trochanteric fractures. JBJS. 1941;23:803.

11. Capener N. The treatment of pertrochanteric fractures. JBJS Br. 1957;39(3):436-7.

12. Taylor MN, Janzen J. Internal fixation for intertrochanteric fractures. JBJS Am. 1944;26(4):707-12.

13. Boyd HB, Griffin LL. Classification and treatment of trochanteric fractures. Ach Surg. 1949;58:853-66.

14. Boyd H, Anderson LD. Management of unstable trochanteric fractures. Surg Gynecol Obstrtrics. 1961;55:853-63.

15. Bendo JA, Weiner LS, Strauss E. Collapse of interochanteric hip fractures fixed with sliding screws. Orthop Rev. 1944;30-7.

16. Dimon JHJC. Unstable intertrochanteric fravtures. JBJS Am. 1967;49(3):440-50.

17. Harrington KJ. The management of communitaed unstable intertrochanteric fracture. JBJS Am. 1973;55(7):1367-76.

18. Sarmiento A. Intertrochanteric fractures of femur. JBJS. 1995;75(3):90-2.

19. Ara D, Newman NP. Unstable intertrochanteric fracture of femur. JBJS Br. 1993;75(3):445-7.

20. Gargan MGR, Simpson A. How effective are osteotomies for unstable intertrochanteric fractures. JBJS BR. 1994;76(5):789-92.
21. Parker MJ, Hando HH, Bhargara A. Conservative versus Operative treatment for hip fractures.

22. The use of ender's pin in extra capsular fractures of hip. JBJS. 1981;63;14-28.

23. Kosygan KP. The gotfried percutaneous compression plate compared with conventional classical hip screw fixation of intertrochanteric fractures of hip. JBJS. 2002;84(1):19-22.

24. Gotfried Y. Percutaneous compression plating of pertrochanteric hip fractures. J Orthop Trauma. 2000;14(7):490-5.

25. Medoff RM. A new device for fixation of unstable pertrochanteric fracture of the hip. JBJS Am. 1911;73(8);1192-9.

26. Lunsjo K, Ceder L, Stigsson L, Hauggaard A. Oneway compression along the femoral shaft with the Medoff sliding plate: the first European experience of 104 intertrochanteric fractures with a 1 year follow-up. Acta Orthop Scand. 1995;66:343-6.

27. Watson JM. Comparison of the compression hip screw with the med off sliding plate for intertrochanteric fractures. Clin Orthop. 1998;(348):79-86.

28. Janzing HM. Percutaneous compression plate verses DHS in treatment of pertrochanteric hip fracture. $\mathbf{J}$ Trauma. 2002;52:293.

29. Hardy DC. Sloted ontramedullary hip screw nail reduces proximal mechanical unloading. Climorthprelat Res. 2003;406:176.

30. Karn NK, Singh GK, Singh MP. Comparison between external fixation and sliding hip screw in the management of trochanteric fracture of femur. JBJS Br. 2006;88:1347-50.

31. Yechielgotfried. Integrity of the lateral femoral wall in intertrochanteric hip fracture an important predictor of reoperation. IBJS. 2007;89:2552-3.

Cite this article as: Kumar ASM, Kumar AB. Proximal femoral nail antirotation II in fixation of intertrochanteric fractures: retrospective and prospective observational study. Int J Res Orthop 2020;6:593-6. 